Studia de Cultura 12(3) 2020

ISSN 2083-7275

DOI 10.24917/20837275.12.3.8

\author{
Mikołaj Spodaryk \\ Uniwersytet Pedagogiczny im. KEN w Krakowie \\ ORCID 0000-0001-8186-3067
}

\title{
Pisarstwo konceptualne i nowe media w dobie konwergencji. Studium przypadku polskich utworów eksperymentalnych
}

\begin{abstract}
Wstęp
Tradycja transmedialnych odczytań dzieł literackich ma już długą historię. Choć sama transmedialność najczęściej używana jest do opisu praktyk narracyjnych mających odsłony w różnych mediach (Jenkins 2007), to można ją też odnieść do historycznych już prób definiowania zjawisk przez pryzmat medium. Warto wspomnieć, uznawane aktualnie za klasyczne, propozycje związku prasy i opowieści narracyjnych czy obecne w Polsce od lat siedemdziesiątych ubiegłego wieku koncepcje Roberta Humphreya (Humphrey 1970) poświęcone przemianom strumienia świadomości i jego związkom z technikami montażu filmowego. Koncepcje te zaowocowały na rodzimym gruncie chociażby poszukiwaniem panoramicznego widzenia u Bolesława Prusa itd. Te ujęcia dotyczyły przede wszystkim bardziej tradycyjnych form gatunkowych (co nie znaczy, że nie eksperymentujących) - w porównaniu z tymi, które w latach sześćdziesiątych XX wieku Dick Higgins (Higgins 2000) określa mianem intermediów - form przekraczających więcej aniżeli tylko zastany gatunek. $\mathrm{W}$ istocie przekraczanie jednego medium w ujęciach transmedialnych jest bliskie ujęciu Higginsa, jednak wiąże się przede wszystkim z kulturą konwergencji i ze spotkaniem „starych mediów” z „elektronicznymi”.

Dziś ta nowość mediów elektronicznych wydaje się nieco trącić myszką. Zjawiska takie jak remediacja czy techniczne metafory poznawcze, które na dobre weszły do naszego języka, stawiają już od dawna media elektroniczne za dość oczywisty punkt odniesienia (co widać między innymi w ujęciach Jaya D. Boltera, Lva Manovicha czy Manuela Castellsa).

Wielu literaturoznawców poza badaniem tematyzacji współczesnych problemów społecznych związanych ze społeczeństwem informacyjnym zaczyna poszukiwać „sieci w powieści” (zob. Woźniakiewicz-Dziadosz 2012). Rozpoznania dotyczą przede wszystkim poziomu poetyki tekstów przybierających krótkie, mozaikowe formy oraz badań dzieł, które są per se utworami transmedialnymi, czy też naśladującymi remediację środowiska elektronicznego (takim przykładem opisywanym już przeze mnie była opowieść graficzna Facecje \#HistoriaCoachemŻycia - zob. Spodaryk 2016).
\end{abstract}


Wreszcie - nie sposób uciec od analizy wpływu nowych mediów na praktyki twórcze, nie wspominając o literaturze elektronicznej, której cechą jest cyfrowy rodowód (Hayles 2011). Jakkolwiek ta ostatnia nie odniosła nigdy specjalnego sukcesu (dotyczy to nawet już dość rozpoznawalnej powieści hipertekstowej), być może $\mathrm{z}$ wyjątkiem minimalistycznych form uprawianych $\mathrm{w}$ przestrzeni portali społecznościowych. Literatura elektroniczna najwyraźniej wyraża odrębność i swoistość swojej poetyki związanej z porządkiem medium / platformy, w której powstała.

W XXI wieku głównym sposobem istnienia literatury, wbrew zapowiedziom futurologów, ciągle pozostaje tradycyjny papierowy obieg, wzbogacony o całkowicie przeźroczyste elektroniczne remediacje książek w postaci e-booków. W tym wypadku sam nośnik w postaci ekranu czy specjalnego czytnika nie ma żadnego znaczenia dla kształtu narracji literackiej. Same narracje, w tym te co wrażliwsze na przemiany języka wypowiedzi poetyckiej, pozostają z bardzo nielicznymi wyjątkami dość zachowawcze, jeśli chodzi o formę narracyjną, graficzną czy przynależność gatunkową. Wreszcie tym, co najłatwiej uznać za literaturę, jest nadal to, co zyskało konsekrację w postaci publikacji z numerem ISBN, wydającą się ważniejszą od recepcji dzieła przez krytyków, których pozycja w polu literackim po 1989 roku mocno osłabła.

Czyżbyśmy zatem strzelali do wróbli, wytaczali ciężkie działa, by badać pojedyncze zjawiska takie jak literatura elektroniczna lub konceptualna czy inne pojawiające się na pograniczu? Tuszę, że nie. Świadczą o tym niektóre zjawiska, które starałem się opisać $w$ artykule poświęconym pojęciu literatury postelektornicznej, podsumowującym wspomniane powyżej problemy (zob. Spodaryk 2016).

W kwestii „postelektroniczności”, „postcyfrowości” pozwolę sobie na pewną dygresję. Funkcjonująca $\mathrm{w}$ angielskim piśmiennictwie kategoria post-digital (postcyfrowy) jest terminem opisowym używanym potocznie na określenie fenomenów powrotu do starych mediów na zasadzie resentymentu, mody bądź ludycznych tendencji związanych z rozczarowaniem technologią (Cramer 2015: 13). W sztukach wizualnych bywa on przytaczany jako zjawisko związane z poczuciem wyczerpania form multimedialnych, które miały nieść ze sobą obietnice nieograniczonych możliwości reprezentacji, czy też na określenie specyficznej estetyki związanej z krytyką wizji postępu niesioną przez wiek cyfrowy oraz ze związanymi z nim ideami teleologicznymi.

Z drugiej strony w ujęciach Davida Berry'ego (Berry, Dieter 2015), Alessandra Ludovica (Ludovico 2012), Floriana Cramera (Cramer 2015) i innych kultura postcyfrowa jest stadium, w którym technologia została całkowicie znaturalizowana. Aktualnie nikogo nie dziwi przemiana dawnych mediów w nowe - zamiana elektronicznego sygnału analogowego na cyfrowy, a więc muzyki na strumienie bitów itd. W konsekwencji postcyfrowość byłaby badaniem wpływu elektronicznych mediów cyfrowych na świat już przez te omawiane media przeobrażony. Podobnie uważa kompozytor i artysta Kim Cascom, upatrujący w postcyfrowości zatrzymanie się w poszukiwaniach innowacyjności na rzecz korzystania z istniejących zdigitalizowanych zasobów. Taką tezę przedstawia także Kenneth Goldsmith w książce Uncreative Writing (Spodaryk 2016). 
Zdaniem Floriana Cramera (Cramer 2015) termin postcyfrowy jest częściowo niedorzeczny, ponieważ niesłusznie implikuje moment historycznego zerwania. Możemy go zaobserwować w pierwszym wspomnianym użyciu, à propos odrzucania technologii cyfrowych. Nie jest absurdalny natomiast jako deskryptor reakcji sztuki na kulturowy wpływ cyfryzacji.

Postcyfrowość, potraktowana jako paradygmat, wiązałaby się z przewartościowaniem całej formacji dyskursywnej związanej z cyfrowością, jako swoistą ideologią - postępu, dostępności, globalizacji itd. W pewnym sensie jesteśmy już od dawna zanurzeni w dyskursie postcyfrowym.

Interesujące mnie pisarstwo konceptualne, o którym zresztą coraz częściej pisze się jako o literaturze, jest zjawiskiem z marginesu pola produkcji literackiej. Wydaje się, że w najpełniejszy sposób (także za sprawą deklaracji programowych jego głównych ideologów) dotyka kwestii materialności języka jako konsekwencji postcyfrowości tej twórczości i konwergencji opisywanej przez Henry’ego Jenkinsa (zob. Jenkins 2007). Dzieła te istnieją najczęściej w tradycyjnej postaci medialnej ot, książki papierowej, ewentualnie e-booka ${ }^{1}$. Wydawane i sprzedawane są w małych, niezależnych oficynach artystycznych, również w Polsce (przez Korporację Ha!art, nieistniejący już Hub Wydawniczy Rozdzielczość Chleba czyli obecny Instytut Ducha, Wydawnictwo piotrszreniawski oraz samizdaty).

Podejmowano próby wyjaśnienia, czym literatura konceptualna jest (Spodaryk 2016; Marecki, Małecka, Spodaryk 2014), wyjaśniając, że chodzi o twórczość podporządkowaną przymusowi obranej procedury twórczej. Czasem związanej z kopiowaniem tekstu, z zestawem procedur, instrukcji nieraz powodujących, że efekt końcowy procesu często bywa daleki od tego, co potocznie uważamy za literaturę, bardziej przypominając kuriozalną bazę danych. Pomysł / koncept / idea, która poprzedza powstanie dzieła, jest uważana za element ważniejszy od samego produktu końcowego. Pisarstwo konceptualne w tym sensie jest ściśle związane ze sztuką konceptualną, o ile nawet nie jest po prostu jej pochodną (dla odmiany jednak uprawianą już nie w polu sztuk wizualnych, a literackim), o takiej, a nie innej konkretyzacji medialnej. Termin conceptual writing jest jednak od sztuki konceptualnej znacznie młodszy, powstał w 2003 roku, mimo że wcześniej w odniesieniu do niektórych dzieł sztuki stosowano termin poezja konceptualna. To, co istotne w rozważaniu pisarstwa konceptualnego, mające stanowić o jego differentia specifica, to fakt, że opiera się ono na próbie przeniesienia praktyk konceptualnych z pola sztuki na pole literackie, rządzące się trochę odmiennymi zasadami i stawkami², w tym innym charakterem instytucji w jego obrębie, metodami konsekracji, rolą aktorów społecznych biorących udział w tej specyficznej grze itp. Pisarstwo konceptualne przekracza jednak pewne kategorie podstawowe dla pola literackiego, takie jak pojęcie oryginalności, autorstwa itp.

${ }^{1}$ Istnieją także konceptualne przykłady literatury elektronicznej, jednak większość twórców deklarujących się jako konceptualiści tworzy przede wszystkim w medium druku, stawiając na różne subwersywne strategie - parafrazując klasyka - „przegrzewania” go.

${ }^{2}$ Pojęć tych używam w rozumieniu Pierre’a Bourdieu za Regułami sztuki (Bourdieu 2001). Na temat miejsca pisarstwa konceptualnego w polu literackim przygotowuję rozprawę doktorską oraz przewiduję dalsze publikacje. 
Aby dać czytelnikom, którzy nie zetknęli się z pisarstwem konceptualnym, pewne wyobrażenie o tym, czym ono jest, proponuję dwa przykłady książek konceptualnych, które ukazały się w Polsce w ostatnich latach. Jedną z nich jest wydana po polsku adaptacja klasycznego PAD Stevena Zultanskiego (zob. Zultanski 2010; Marecki 2016), będąca niczym więcej jak katalogiem przedmiotów znajdujących się w mieszkaniu autora, spisanych pokój po pokoju, a następnie podzielonych według dwóch kategorii: rzeczy, które autor uznaje za możliwe do udźwignięcia za pomocą penisa lub nie. Książka ta zainaugurowała konceptualną serię opublikowaną przez jedno z wydawnictw. Drugą jest przekład (poprzez wykonanie go na nowo) książki Yeddy Morrison (zob. Morrison 2011, 2018), opierający się na wypreparowaniu opisów dzikiej natury z Jądra ciemności Josepha Conrada i usunięciu z książki wszystkich śladów obecności człowieka.

\section{Nowe konceptualizmy i nowe media}

Kategoria pisarstwa konceptualnego budzi pewne kontrowersje. Niejasne są jego granice, niejasny rodowód. Teoretycy chętnie sięgają do tradycji awangard literackich z początku XX wieku, zamieszczając odpowiednie teksty w antologiach programowych, takich jak Against Expression pod redakcją Craiga Dworkina i Kennetha Goldsmitha (Dworkin, Goldsmith [red.] 2011). Wśród tekstów znajdziemy dzieła kojarzone zarówno z polem sztuk wizualnych, jak i literatury. Oznaczałoby to, że rodowód literatury konceptualnej nie jest elektroniczny, jednak cyfrowość elektroniczna stanowi dla omawianej twórczości konceptualnej główny punkt odniesienia i odpowiada (przynajmniej według Kennetha Goldsmitha i Marjorie Perloff, zob. Spodaryk 2016) za jej popularność w pierwszej dekadzie XXI wieku. Wiąże się to z nowymi możliwościami technicznej reprodukcji i przetwarzania tekstów, z praktykami pisarskimi związanymi z elektronicznym środowiskiem cyfrowym, a także z wszechobecną tekstualnością interfejsów (również na poziomie metadanych). To, na ile te narzędzia związane są z przekształceniem świadomości piśmiennej, można pozostawić kwestią otwartą. Zdaniem Goldsmitha i Perloff doświadczenie wyniesione z mediów elektronicznych wiąże się z silnym akcentowaniem materialności tekstu (zob. Spodaryk 2016). Oczywiście należałoby zaznaczyć, że istnieją także inne spojrzenia na pisarstwo konceptualne, w mniejszym stopniu akcentujące rolę nowych mediów (Fitterman, Place 2013), jednak polska recepcja (z pewnymi wyjątkami) zdecydowanie poszła w stronę nurtu „elektronicznego”. Związane jest to z zainteresowaniem wydawców polskich tekstów praktykami artystycznymi związanymi właśnie z subwersywnymi działaniami w obrębie nowych mediów, a także z popularyzacją i wydawaniem przez nich literatury elektronicznej w przeszłości (chodzi tu przede wszystkim o Korporację Ha!art).

\section{Typologia punktów stycznych}

Tworzenie typologii konwergencji, które zachodzą między literaturą i innymi mediami, nie wydaje się szczególnie bezpieczne - trudno bowiem o stworzenie propozycji, która nie byłaby nazbyt wąska lub za szeroka. Proponowałbym robocze 
ujęcie sprowadzające się do czterech typów podstawowych relacji cyfrowe media elektroniczne - literatura:

1) dzieła o cyfrowym rodowodzie, w tym przede wszystkim literatura elektroniczna;

2) tematyzujące problemy medialne, metafory poznawcze, w tym związane z modelami reprezentacji wiedzy i języka z mediów elektronicznych;

3) powstałe na styku różnych mediów, w tym digital storytelling, utwory transmedialne;

4) dzieła o cyfrowym rodowodzie lub remediowane, o formie narzuconej przez nowe medium, lecz niebędące obiektami cyfrowymi (a więc niebędące literaturą elektroniczną per se).

Te cztery typy rzecz jasna nie wykluczają się wzajemnie (w niektórych punktach mogą się uzupełniać).

Do kategorii 1 można zaliczyć powszechnie niepopularne dzieła literatury elektronicznej wszystkich trzech generacji. Ograniczając się tylko do kilku wczesnych (lecz przynajmniej zauważonych przez badaczy) przykładów z polskiego kontekstu, warto wymienić: Blok Sławomira Shutego, Koniec świata według Emeryka Radosława Nowakowskiego, Schemat Konrada Polaka, wiersze Karoliny Giełżyńskiej, boty i generatory Piotra Mareckiego, programy oraz gry Leszka Onaka i wiele innych.

W ramach kategorii 2 możemy mówić o zachowawczych formach narracyjnych, takich jak niezbyt interesująca powieść Piotra Czerniawskiego Pigułka wolności, tematyzująca między innymi problemy uzależnienia od mediów społecznościowych. Pigułka wolności nie będzie miała nic wspólnego z relacjami z kategorii 1, 3 i 4. Nie będą też miały z nimi nic wspólnego próby naśladowania języka sieciowego. Opowieścią transmedialną z kategorii 3 będą na przykład takie twory jak opisywana przeze mnie w innym artykule Facecje \#HistoriaCoachemŻycia. Posiada ona rozwinięcia w postaci serialu i audycji na YouTubie oraz historii rozwijanej na portalu Facebook. Przykładem bardziej ambitnych utworów z tej kategorii są powieść Big Dick Wojciecha Bruszewskiego czy Stilleben Jakuba Woynarowskiego i Jakuba Argasińskiego. Obie te pozycje są książkami z rozszerzoną rzeczywistością.

Zatrzymajmy się teraz przy czwartym typie relacji, który może się okazać szczególnie interesujący w kontekście przejścia od literatury elektronicznej do postelektronicznej i może zawierać w sobie wybrane cechy utworów z pozostałych kategorii.

Książki takie jak Pamiętnik blondynki (pierwszy blog wydany jako książka), wspomniane wcześniej w ramach omawianej kategorii 2 Facecje..., utrzymywana w poetyce pasty twórczość Malcolma XD czy zyskujące książkową konkretyzację profile z portalu Facebook (takie jak komiksy internetowe z durnowatej serii Pan Buk Ogarniacz Życia, Kołonotatnik z bohaterem i inne, a także interesująca mnie literatura konceptualna) często powstają najpierw w środowisku elektronicznym, by następnie zostać wydane w tradycyjnym obiegu w postaci książki. Co więcej, wspomniane utwory remediują środowisko sieciowe w ramach tak zwanego mimetyzmu formalnego. Trzy pierwsze popularne opowieści raczej nie mają ambicji krytycznej wobec formacji medialnej, stanowią raczej przykład reprodukcji nawyków lekturowych i praktyk sieciowych, równie dobrze mogłyby reprezentować kategorię 2. 
Projekty artystyczne spod znaku konceptualizmu natomiast stawiają sobie za zadanie problematyzację przepływu tekstu z jednego medium w inne.

Spróbujmy zatem zobaczyć, jak do tej typologii odnosi się polska recepcja pisarstwa konceptualnego. Wyłączam z badania kategorię 1, i tak już dobrze rozpoznaną w Polsce za sprawą licznych studiów poświęconych różnym realizacjom literatury elektronicznej. Pozwalam sobie zaproponować trzy krótkie szkice na temat wybranych utworów konceptualnych, odsłaniające nie tylko ich związki z mediami elektronicznymi, ale i z polem literackim. Mam nadzieję, że pozwoli to na uchwycenie ogólnej, nie tylko medialnej problematyki tej twórczości mieszczącej się w ramach zaproponowanej typologii, ale i innych ważkich kwestii przez nią poruszanych.

\section{Tematyzacja - Wiersze za sto dolarów Piotra Mareckiego}

Mechaniczny Turek to obrosła wieloma legendami mistyfikacja pierwszej maszyny szachowej. Składał się na nią pulpit w formie biurka, na którym znajdowała się szachownica oraz poruszana skomplikowaną siecią linek i dźwigienek figura mechanicznego gracza. Część pulpitu zawierała imitujące prawdziwy mechanizm kółeczka zębate. Wynalazcą cudownej maszyny był Wolfgang von Kempelen. Maszyna jednak nie miała nic wspólnego z automatem ani z komputerem. Wewnątrz skrzyni ukryty był mistrz szachowy, który operował ramieniem Turka.

Uruchomiona w 2005 roku strona - należąca do amerykańskiego przedsiębiorstwa handlowego Amazon - Amazon Mechanical Turk to usługa pozwalająca na zlecanie prostych zadań (tzw. HIT - Human Intelligence Task). Użytkownicy zarejestrowani jako zleceniodawcy mogą zlecać innym użytkownikom - zarejestrowanym jako zleceniobiorcy - różne prace. Najczęściej należy do nich tagowanie zbiorów danych lub zdjęć, pisanie krótkich notek marketingowych i inne, w których niemożliwym bądź nieopłacalnym jest używanie sztucznej inteligencji. Paralela między historycznym a współczesnym Mechanicznym Turkiem jest tu dość oczywista - zarówno pracownicy, jak i zleceniodawcy są ukryci przed sobą, kryją się za kodem składającym się z szeregu cyfr i liter, co zapewnia całkowitą anonimizację użytkowników. Kwoty oferowane przez użytkowników zleceniodawców są zazwyczaj niskie, czasem nie osiągają nawet 1 dolara. Co więcej, użytkownik wykonujący pracę otrzymuje wynagrodzenie po jej wykonaniu - pod warunkiem zaakceptowania rezultatów przez zleceniodawcę.

Wydana w serii konceptualnej wydawnictwa Ha!art książka Piotra Mareckiego Wiersze za sto dolarów jest luźną adaptacją Of the Subcontract Nicka Thourstona. W całości powstała jako wynik zlecenia przez Mareckiego anonimowym użytkownikom Amazon Mechanical Turk następującego zadania:

[...] napisz wiersz po polsku. Napisz wiersz współczesny po polsku. Wiersz nie może być nigdzie wcześniej publikowany. Prawa autorskie przechodzą na requestera [zleceniodawcę - przyp. M.S.]. Wiersz nie może być skopiowany z internetu. Wiersz może być na dowolny temat (Marecki 2017: 51).

W trakcie realizacji projektu Marecki uszczegóławiał i zmieniał oczekiwania względem zadania, podając przykłady utworów Tomasza Pułki, Dominiki Dymińskiej 
i innych współczesnych poetów. Książka jest więc wyborem Mareckiego, który jest jej autorem, jednak nie będąc autorem wierszy (mimo zastrzeżenia, że staje się właścicielem praw autorskich). Jest to oczywiście celowo skomplikowana sytuacja, casus nieprzewidywany przez prawo autorskie, zakładające niezbywalność praw osobowych. Niemniej należy zaznaczyć, że podobnego rodzaju praktyki są dość powszechne i funkcjonują „poza nawiasem” prawa. Przykładem są oczywiście usługi ghostwritingu, często związane z próbami konwersji kapitału ekonomicznego na kapitał społeczny czy kulturowy, takimi jak biografie polityków i celebrytów.

Tytułowe sto dolarów to pula pieniędzy przeznaczona na wynagrodzenia dla Mechanicznych Turków. Wiersze w książce są uszeregowane według kwot przeznaczonych dla ich autorów - począwszy od 0,22 dolara, po 10 dolarów. Piętnaście z wierszy zostało napisanych za mniej niż 1 dolara, dziewięć kolejnych za 1 dolara, cztery za 2 dolary, dwa za 5 dolarów i dwa za 10 dolarów.

Mniejsza o treść wierszy, jak można się domyślić, stanowią one raczej przykład pisarstwa, które zawiedzie miłośników poezji (może z kilkoma zabawnymi wyjątkami). Fakt wydania ich w formie książki, w wydawnictwie o silnej pozycji w polu literackim, ma wobec całego przedsięwzięcia moc konsekrującą. Czemu służy także bogato opracowane posłowie, wyjaśniające pomysł, a także inne zabiegi, eksploatujące coś, co można by określić mianem poetyki „książkowości”. Chodzi tu między innymi o dobrane przez Mareckiego blurby - zwłaszcza tekst Mai Staśko, o bardzo dwuznacznym wydźwięku, posiadający realnie krytyczny sens w stosunku do etyczności projektu:

Tak brzmi poezja tworzona w ramach wyzysku, nieopłacalnej bądź skrajnie nisko płatnej pracy, skazana na decyzję bawiącego się swoją władzą pana od poezji, który wydaje ją w książce pod własnym nazwiskiem w swoim wydawnictwie. Tak brzmi polska poezja współczesna. A tak brzmi nieopłacalny blurb. Maja Staśko 0,00 \$.

Staśko swym blurbem, który w kontekście książki należy traktować ironicznie - gdyż projekt Mareckiego ma na celu problematyzowanie, a nie reprodukowanie wyzysku (czy to robi, to osobna kwestia) - trafnie podsumowuje sytuację pola literackiego, zdominowanego przez mężczyzn pokolenia transformacji.

Podsumowując ten wątek, książka Mareckiego stanowi występek przeciw instytucji autorstwa, problematyzuje problem pracy, dość newralgiczny dla pola zakładającego autonomiczność. Jak zauważa Pierre Bourdieu, twórcy, którzy zarabiają na swojej twórczości, od niepamiętnych czasów traktowani są przez uprawiających „sztukę czystą” za co najmniej podejrzanych, a nawet niegodnych miana artystów. Bywa, że powodzenie w polu może być uznane za kompromitację (Bourdieu 2001: 182). Pokutuje to w Polsce szczególnie w słynnych i sztucznych dychotomiach artysta - rzemieślnik / wyrobnik pióra itd. Dotyczy także twórców literatury gatunkowej, uważanych powszechnie za gorszy sort pisarzy. Mimo że książkę Marecki wydał w swoim wydawnictwie, zrobił to jednak za własne pieniądze, cały dochód przeznaczając na finansowanie fundacji Korporacja Ha!art. Tym samym powielił typowy awangardowy gest związany z ekonomią na opak.

Traktowanie pisarstwa wykonywanego przez Turki, jak chciałby Marecki, jako osobnego gatunku twórczości słownej (Marecki 2017: 52) jest tylko pozornie 
problematyczne. Mamy tu do czynienia z praktyką pisania niekreatywnego, dopuszczającą dużą przypadkowość; bohaterem książki Mareckiego jest ogólnie rozumiany „wiersz współczesny”. Sama praktyka pisania przy użyciu Mechanicznych Turków w tradycyjnie rozumianej genologii nie czyni przesłanki, by mówić o nowym gatunku. Za tezą Mareckiego przemawia jednak wykorzystanie określonej platformy, której wpływ nie jest obojętny na kształt danej twórczości oraz możliwość jej wielokrotnego wykorzystania. Byłoby to więc słuszne ujęcie związane z otwarciem badań genetycznych na kontekst kulturowy. A także gest wymierzony przeciw całej tradycji literackiej opartej na paradygmacie oryginalnego geniusza.

Przede wszystkim jednak Wiersze za sto dolarów można interpretować jako opowieść o spełnionej kapitalistycznej dystopii, w której rola technologii sprowadza się do usprawnienia kapitalistycznego wyzysku. Zamiast przynosić wolność od pracy, jak chcieliby dziewiętnasto- i dwudziestowieczni utopiści z Bertrandem Russellem w roli obrońcy lenistwa na czele, maszyny zamieniają się z człowiekiem miejscami. Logika przeniesienia kryjąca się pod metaforą Mechanicznego Turka zrównuje człowieka z maszyną. Hasło Amazona „zdobądź dostęp do globalnej siły roboczej 24/7" brzmi jak spełnienie mokrego snu Departamentu Obrony Stanów Zjednoczonych, badającego funkcjonowanie pasówki białobrewej. 0 tym i o reżimie dyspozycyjności, wydajności i aktywności pisał Jonathan Crary w swojej książce 24/7. Późny kapitalizm i koniec snu.

Interfejs, a więc i technologia, będąca przedmiotem uwagi Wierszy za sto dolarów, jest cudownym narzędziem globalizacji, narzędziem utrwalania pewnej szkodliwej logiki, związanej z niekontrolowanym przez nikogo outsourcingiem pracy, w której jedyną instancją jest zleceniodawca. Choć eksperyment jest w gruncie rzeczy niewinny, w pewnym sensie i zabawny, to poprzez wspomniane wcześniej umiejscowienie w kontekście problemów pola literackiego, czy też każdego innego pola związanego z realną pracą ( $\mathrm{w}$ tym z kontekstem polityki firm outsourcingujących pracę na Daleki Wschód), ukazuje realną przestrzeń nadużycia.

Kolejnym realnym problem tematyzowanym przez koncept Nicka Thurstona, przełożony za sprawą Mareckiego na język polski, jest właśnie demitologizacja technologii poprzez ukazanie jej uwikłania w negatywne procesy społeczne, niejako wpisane w ich projekt. Optymizm projektantów serwisu Amazon z początku XX wieku czy optymistyczna narracja o wzrostach ekonomicznych w regionach inwestycyjnych jest jedną stroną narracji, drugą są realne protesty pracowników przedsiębiorstwa najniższego szczebla, coraz częściej protestujących wobec standardów pracy ${ }^{3}$.

Mechanical Turk obsługuje głównie anglojęzyczną część świata, prawdopodobnie wejdzie niedługo na rynek polski. Już teraz jego użytkownicy pochodzą z całego świata. Choć praca jako Mechaniczny Turek jest dobrowolna, to niesie ze sobą dość przerażający bagaż ideologiczny. Jest nim optymalizacja kosztów przez

${ }^{3}$ http://wiadomosci.gazeta.pl/wiadomosci/7,114883,24310794,pracowniczka-amazona-pisze-o-katorzniczej-pracy-w-swieta-firma.html (dostęp: 31.05.2020). 
przedsiębiorców, zwiększenie elastyczności zatrudnienia i redukcja kosztów. Jednym zdaniem, wszystko co sprzyja demontażowi podstawowego bezpieczeństwa socjalnego ${ }^{4}$.

\section{Opowieść transmedialna - Da Capo al Finne Krzysztofa Bartnickiego}

Da capo al fine jest terminem dotyczącym notacji muzycznej, oznaczającym konieczność powtarzania utworu od początku do końca. W tytule książki Krzysztofa Bartnickiego jest zatem dość oczywiste nawiązanie do struktury Finnegans Wake przetłumaczonego przez niego i stanowiącego kanwę omawianej w tym podrozdziale książki, zakładającej zapętloną, połykającą własny ogon lekturę, bez początku i końca.

Książeczka Bartnickiego ukazała się 2012 roku w klimacie (podgrzewanym specjalnie przez publicystów i autorów recenzji) teorii spiskowej. Czy Joyce zakodował w swoim dziele utwory Chopina i Haydna?, Polak złamał kod Joyce'a ${ }^{5}$ - to tylko niektóre sensacyjnie brzmiące nagłówki tekstów dziennikarskich na popularnych portalach. Szum medialny nie bez znaczenia i na czasie, mając na uwadze ówcześnie trwającą jeszcze popularność książek w stylu Kodu Leonarda da Vinci, doszukujących się w klasycznych dziełach treści ukrytych. Sam autor o swojej pracy wypowiadał się z dystansem, w zdecydowanie ironicznym duchu.

Nawiązując do eksperymentów Johna Cage'a, Bartnicki dosłownie potraktował możliwość myślenia o Finnegans Wake jako o partyturze. Z oryginalnego tekstu Joyce'a usunął wszystkie odstępy międzywyrazowe oraz litery, pozostawiając tylko te przekładalne na dźwięki, a więc: c, d, e, f, g, a, h, b (zachowując podział na wielkie i małe litery). Zabieg przepisania Finnegans Wake nie obył się bez pewnych trudności - wyspacjowane fragmenty z Joyce’a (w których nie mamy do czynienia z jednolitym blokiem tekstu) czy przypisy autora zostały według odpowiedniego klucza dopasowane do jednolitego łamu tekstu Da Capo al Finne. Powstała książka potworna, treścią przypominająca jeden z nic nieznaczących tomów z Borgesowskiej Biblioteki Babel.

Książkę Bartnickiego należy traktować jako materialną całość - swoistą „rzeźbę słowną", której bazą jest zestandaryzowane wydanie Finnegans Wake liczące 628 stron, co nie pozostaje bez znaczenia dla większości interpretacji wyłuskujących materialną stronę dzieła Jamesa Joyce’a. Da Capo..., jak już zauważyłem, mogące być artefaktem z Biblioteki Babel, nie jest jednak dziełem reprezentacyjnym dla konkretyzmu.

Da Capo... to jednak rzeczywiście partytura oparta na dziele Joyce'a, zapis wszystkich wyekstrahowanych z książki symboli dźwięków, niezawierający jednak żadnych wskazówek co do wykonania: tempa, metrum, dynamiki, barwy itp. Czytelnicze wybory mogą prowadzić do odnalezienia w tekście Da Capo al Finne kombinacji dźwięków przypominających znane już melodie. Konieczne jest jednak

${ }^{4}$ Obecna sytuacja związana z pandemią wirusa SARS-CoV-2 obnażyła dramatyczną sytuację pracowników zatrudnianych na umowy cywilnoprawne lub wypchniętych na samozatrudnienie.

${ }^{5}$ https://culture.pl/pl/artykul/polak-zlamal-kod-joycea (dostęp: 31.05.2020). 
pominięcie niektórych z nich lub sprowadzenie ich do roli ozdobników, a także samowolne nadanie dźwiękom czasu trwania, uwzględnienie pauz, określenie chromatyki, tempa. Idąc tym tropem, można znaleźć szeregi dźwięków, które pozwalają na wyabstrahowanie, z niemałym trudem, melodii autorstwa Haydna i Chopina.

Ale także z ciągów:

adchdhdagebegaehehaeeaeaaaaaheaaceeechadhagabeeaedheffaeeabehhahgeheachcheddefheacccaef

ahfeeahecheeedcaeeheaeachacehadaehhegfaaceaaeabaaaehebefeafebegeddhahadeebeedhHeehehafee

czy

eefaaghcadcceeabaeahecegahhedeeecehcheeceaeceadffeeafeedbegheeacdeffbefehaddedceaeaddheageh,

po nadaniu odpowiednich wartości dźwiękom można wyłuskać - jak czyni to Krzysztof Bartnicki - kolejno melodie ścieżek dźwiękowych z filmów Conan Barbarzyńca, Ojciec Chrzestny i Gwiezdne wojny.

Wszystkie powyższe przykłady przytoczył autor Da Capo al Finne; na SoundCloudzie. Pod adresem internetowym https://soundcloud.com/gimcbart znajduje się projekt będący kontynuacją Da Capo al Finne. Wybrane przez Bartnickiego fragmenty Da Capo... są zinstrumentalizowane (przy użyciu elektronicznych narzędzi) i stosownie opisane - każdy ciąg literowy jest przypisany także do fragmentu Finnegans Wake, z którego został zaczerpnięty.

Prawdopodobieństwo znalezienia długiego ciągu literowych znaków muzycznych mogących przypominać znaną melodię w dowolnym tekście jest dość niewielkie. Jesteśmy skazani w Da Capo... (ale gdyby stosownie obrobić niniejszy tekst, to i w nim, ale też w każdej dowolnej książce) jedynie na urywki. Choć - marna może z tego pociecha - i tak prawdopodobieństwo to jest większe niż natrafienie na jakikolwiek sensowny twór słowny w dowolnym języku w Bibliotece Babel.

W istocie w całym eksperymencie Bartnickiego nie chodzi tylko o muzykę (chociaż muzyczne realizacje z Da Capo al Finne są spektakularne, a projekt rozwijany na platformie SoundCloud nadaje książce kolejny wymiar, związany z rozszerzeniem rzeczywistości książki. Tłumacz Finneganów trenu stawia pytanie z rodzaju dziedziny postmodernistycznej tekstualności. Na część postawionych we wstępie do Da Capo... pytań udziela jasnych odpowiedzi („Czy Joyce zaplanował długość bloku Da Capo al Finne? - Tak pośrednio, skoro zaplanował długość Finnegans Wake. A czy zaplanował częstość i kolejność liter bloku? - Nie. - Czy skomponował melodie ukryte w bloku? - Bezwiednie. - Więc jest ich autorem? - Nie, ponieważ nie miał świadomości procesu kompozycji"; Bartnicki 2012: 6). Inne pozostawia prowokacyjnie otwarte - zwłaszcza o plagiat w przypadku wykonania melodii zawartych w Da Capo..., których fragmentów jest praktycznie niezliczona ilość, jeśli potraktować książkę jako partyturę aleatoryczną (w której znaczenie ma przypadek, brak pewnych wskazówek co do wykonania i duża rola odbiorcy w odczytaniu). Odpowiedź dostarczana przez podręczniki prawa autorskiego oddala ten problem, 
mimo istnienia teorii jednorazowości statystycznej, która zakłada, że „dzieło ma być unikalne w tym sensie, że statystycznie istnieje niewielkie prawdopodobieństwo, by ktoś stworzył identyczne dzieło" (Ślężak 2012: 106). Decydujące jest kryterium piętna osobistego stosowane w polskim prawodawstwie. Przypadkowe, ale i celowe, wykonanie fragmentu z Da Capo... opiera się na indywidualnej interpretacji, naddaniu wartości dźwiękom rozlokowanym w tekście przypadkowo (i to w praktycznie każdym tak obrobionym tekście!). W tym też sensie muzyczne opracowania Da Capo... dostępne na SoundCloudzie są dziełami (wynikiem konceptu) i interpretacjami Bartnickiego, nie zaś Prodeusa, Williamsa czy Chopina.

A czy Joyce’a? Należałoby założyć, że nie, gdyż ich istnienie nie było przez niego zamierzone. Ciągi liter Da Capo..., traktowanego jako partytura aleatoryczna, są wynikiem działania samego tylko języka, którym Joyce napisał Finnegans Wake - w tym wypadku jego anglocentrycznego wariantu, w którym częstotliwość liter pozostaje pochodną leksyki. To powrót do ontologii komunikacji wyznaczonej przez europocentryczną (bo opartą na alfabecie łacińskim) Bibliotekę Babel, graniczną metaforę tekstualności, ale i języka w ściśle strukturalistycznym rozumieniu. Wszystko tu istnieje potencjalnie $\mathrm{w}$ uniwersum liter i znaków, modernistyczny geniusz jest związany systemem używanego przez niego języka, niezależnie od tego, jak bardzo by poszerzał jego granice swoją mową.

Bartnicki nieprzypadkowo wybiera właśnie Finnegans Wake jako surowiec (przewija się on w innych jego konceptualnych pracach, w tym Fu wojny i Prospekcie emisyjnym - dwóch innych wzorowych przykładach pisarstwa konceptualnego). Ostatnie dzieło Joyce’a to tekst obrosły tyloma mitami i legendami co święte księgi, zaś akademicka refleksja mu towarzysząca zamieniła się w rodzaj wielkiej egzegezy, w której to niejednokrotnie można spostrzec tendencję do doszukiwania się w dziele Joyce’a prądów myślowych znacznie wyprzedzających epokę pisarza. Gest Bartnickiego tworzącego Da Capo al Finne jest właśnie - by użyć popularnego w sieci określenia na prowokacyjne antyspołeczne zachowanie na forach dyskusyjnych - „trollingiem” całego „przemysłu okołojoyce’owskiego”, ale i radosną profanacją Finnegans Wake.

Ponadto transmedialny wymiar, który Bartnicki nadał swojemu projektowi, za sprawą wypowiedzi fikcjonalizujących dzieło (podchwyconych przez dziennikarzy) na temat rzekomego „kodu Joyce'a” oraz elektronicznych instrumentalizacji muzycznych Da Capo al Finne służy tworzeniu strategii uwiarygadniających nie tylko książkę jako partyturę, ale cały poziom metafikcji związany z istnieniem rzekomego kodu Joyce'a, co generalnie stanowi żart z całego sektora produkcji heteronomicznej pola literackiego opartego na sensacji i szybkim zysku.

Transmedialność stanowi też u Bartnickiego nową formę heretyckiej dystynkcji, w której narzucającą się, elitarną kompetencją jest wszystkożerność kulturowa. Odbiorcom dzieł Bartnickiego nie wystarczy już kompleksowa znajomość twórczości Joyce’a, jeśli nie będą znali kontekstów w postaci wspomnianych wcześniej Gwiezdnych wojen, wprowadzanych przez Bartnickiego na „salony”, kwestionując dominujący i prawomocny gust.

Zestawienie Joyce'a z Prodeusem czy Lucasem jest nie tylko zabawne, ale też pouczające. Wspomniana „wszystkożerność” jest nową kompetencją kulturową 
związaną z opisywaną przez Henry'ego Jenkinsa kulturą konwergencji, powodującą erozję tradycyjnych wyznaczników i podziałów na wysokie / niskie. U Bartnickiego opiera się także na przejętym z marketingu działaniu typu tie in, o którym pisała bardzo interesująco Inez Okulska (Okulska 2016: 52).

Wszystkożerność z punktu widzenia teorii Pierre'a Bourdieu jest tylko pozornie problematyczna i nie wiąże się z odejściem od ściśle klasowego modelu konsumpcji. Wzory konsumpcji nie są stałe, a model wszystkożerności, chociażby oparty u klas wyższych na krytycznym czy ironicznym podejściu, na przykład do filmów klasy B, związany jest przede wszystkim z możliwością dostępu do różnych dóbr, jak i z kompetencją - w tym kompetencją medialną, która ją umożliwia. Dzieło Bartnickiego tego wymaga, co sytuuje je poza obszarem heterogenicznym, a jednocześnie w pozycji herezji w stosunku do z natury zachowawczego pola literackiego.

\section{Cyfrowy rodowód - Ubu Król w tłumaczeniu maszynowym}

Usługa Google Tłumacz (Google Translate) ma swój początek w 2006 roku jako mechanizm tłumaczenia maszynowego wykorzystującego model analizy statystycznej tekstu. W wypadku usługi Google oznaczało to, że zamiast korzystać ze zdefiniowanej dla maszyny funkcji słownictwa i gramatyki, translator wykorzystywał gotowe teksty z języka źródłowego i docelowego, a więc również istniejące przekłady, z wykorzystaniem których tworzył model tłumaczenia oparty na statystyce (Och 2006). Tymi tekstami są oczywiście dostępne w usługach Google dokumenty, strony internetowe itd. W Google Translate tłumaczone były całe frazy, mapowane na podstawie statystycznej historii użyć, których maszyna uczy się na podstawie porównywania dostępnych jej korpusów (Koehn i in. 2003).

Takjeszcze do niedawna wyglądały podstawy działania translatora. Odpowiadał on czasem za kuriozalnie śmieszne przekłady, zwłaszcza z języków dominujących, takich jak angielski, na peryferyjne - czy wzajemnych tłumaczeń z języków peryferyjnych. Od 2016 roku Google rozwija projekt oparty na inteligentnych sztucznych sieciach neuronowych. Porównanie automatycznego tłumaczenia sprzed paru lat z dostępnymi dzisiaj - zwłaszcza z języka angielskiego - daje obraz rzeczywistej rewolucji, która dokonała się zaledwie w przeciągu czterech lat.

Wracając jednak do początków: praca nad tłumaczeniem maszynowym leży u podstaw fantazji o świecie bez komunikacyjnych barier. „Kali krowa jeść mięso”, którym można było streścić jakość tłumaczenia automatycznego, leży u podstaw żartów z tej utopii, wspieranej przez „upośledzone intelektualnie roboty”. Dziś, optymistycznie patrząc w przyszłość, rozwój narzędzi Google w tym obszarze daje coraz mniej powodów, by śmiać się w kułak. Wprowadzone wsparcie maszyny neuronalnej dla języka polskiego świetnie sobie radzi w 2020 roku. 0 ile same mechanizmy działania są trudne do zrozumienia bez specjalistycznej wiedzy (a może nawet niemożliwie, gdyż algorytmy są tajemnicą przedsiębiorstwa), o tyle interfejs jest intuicyjny, łatwy i przystępny dla każdego użytkownika.

Świadectwem nieudolności poprzedniej formy tłumaczenia automatycznego jest wydany w 2015 roku Ubu Król Alfreda Jarry w przekładzie maszynowym Google Translate. Czy też jak sugeruje okładka - w przekładzie bądź spolszczeniu 
autorstwa Aleksandry Małeckiej i Piotra Mareckiego. Duo niewątpliwie włożyło pracę w powstanie książki, zwłaszcza jeśli rozpatrujemy pisarstwo jako wykorzystywanie wszelkich dostępnych narzędzi.

Ubu Król przetłumaczony przez Google jest tekstem bełkotliwym, niemającym nic wspólnego z poprawnością językową. Nie nadaje się do lektury, przynajmniej w potocznym sensie. Cała akcja dramatu została zaburzona, dialogi bohaterów bywają całkowicie niezrozumiałe - lub też pozostają w zupełnie luźnym związku z oryginalnym sensem. Na tym można by zakończyć dowolną recenzję.

Warto wspomnieć jednak o wstępie do książki, będącym sklejką czy kolażem najbardziej sztampowych wypowiedzi na temat literatury. Otóż nowy przekład jest przedstawiony jako „interesująca propozycja” bądź „innowacja” względem starych tłumaczeń oraz ich losów itd. Tekst jest rzeczywiście remiksem różnych wypowiedzi o przekładach znanych utworów literackich, wyborem totalnie pustych znaczeniowo, napuszonych wypowiedzi krytycznoliterackich. Co oczywiście jest całkiem zabawne, pokazywać ma jednak instytucjonalne uwikłanie tekstów literackich - począwszy od uzyskania konsekracji w wyniku samej publikacji, po ich normatywne włączenie do kanonu, opatrzenie komentarzem przez aktorów pola takich jak krytycy, recenzenci itd., biorących aktywny udział w wytwarzaniu przedmiotów kulturowych. Ta książka jest również żartem z oczekiwań czytelniczych.

Istnieje jednak jeszcze jeden poziom odczytań Ubu Króla wydanego przez Ha!art w 2015 roku. Kontekstem jest bowiem globalna sieć informacyjna, z którą związany jest Google Translate. Jak wspomniałem, korzysta on z korpusu tekstów znajdujących się w zasobach jego bibliotek. Tak jak w wielu nowoczesnych ujęciach można traktować przekład jako praktyczną metodę badań w działaniu (Małecka, Marecki 2018: 101), tak w wypadku tłumaczenia maszynowego Google Translate dostarcza nam materiału opartego na istniejących korpusach. Gdybyśmy chcieli dowcipnie spuentować możliwy wynik badania, to wiedza, którą można z tego faktu wyciągnąć, jednoznacznie wskazuje na to, że w roku 2015 usługa Google nie radziła sobie zbyt dobrze z językiem francuskim. To, co przedstawiam jako dowcip, jest jednak istotnym raportem na temat kwestii relacji języków hegemonicznych z peryferyjnymi. Jeśli Google Translate czerpie z baz danych, repozytoriów sieciowych, to kwestia wadliwości tłumaczenia w wypadku analizy kontekstowej i statystycznej może wskazywać na niedorozwój w obszarze wiedzy związanej z tłumaczeniami polsko-francuskimi. Ponadto część tłumaczeń opartych na Translatorze Google wiąże się z dwustopniowym przekładem - filtrowanym przez język angielski. To, że angielski jest w Dolinie Krzemowej językiem o statusie hegemona (choć ma konkurencję w postaci chińskiego), zakrawa na oczywistość, jednak zyskuje ciekawy i symboliczny wymiar w kontekście zniekształcenia tekstu literackiego. Wreszcie, jak pokazuje casus innych algorytmów Google - jak chociażby wyszukiwarki podpowiadającej najczęstsze lokalnie hasła wyszukiwania - przekład będący przepracowaną przez maszynę sumą istniejących dokumentów może kierować nas w stronę różnych - mniej lub bardziej mętnych - koncepcji reprezentacji zbiorowej (nie) świadomości. Niewątpliwie tłumaczenie statystyczne wykorzystuje wiedzę o najczęściej wykorzystywanych zwrotach, co wobec braku ścisłego stosowania uzusu językowego w internecie może być przyczynkiem do ciekawej teorii. Jak zauważa 
Małecka, „odkrywamy pewne prawidłowości dotyczące zjawisk językowych i społecznych. Co ciekawe, na przykład całkiem naturalnie w tłumaczeniu Google wychodzą sformułowania dotyczące militariów" (Małecka, Marecki, Spodaryk [red.] 2015: 65). Być może badanie stylometryczne tekstu Ubu Króla z 2015 roku mogłoby być ciekawym eksperymentem poznawczym, jednak ilość dokumentów, z których korzysta program, kierowałaby raczej w stronę badań zbiorowego stylu, aczkolwiek ciężko byłoby o jasne wnioski z takiego rodzaju badania. Niemniej podobnie jak w wypadku innego projektu, który narodził się na Facebooku - chodzi o popularne w swoim czasie „wiersze z Google” powstałe z wykorzystaniem podpowiedzi wyszukiwarki - takie traktowanie, nawet na prawie metafory, przekładu dokonanego przez Mareckiego i Małecką jest kuszące. Byłoby to jednak badanie stanu na konkretny moment 2015 roku, gdyż ilość tekstów w bibliotekach Google nieustannie przyrasta, co powoduje płynność tłumaczenia, nowy zaś mechanizm oparty na Google Neural Machine Translation zaczyna likwidować liczne pomyłki translatora.

\section{Zakończenie}

Zaproponowana $\mathrm{w}$ tym opracowaniu typologia w pewnym sensie pozwala na uporządkowanie dotychczasowego stanu wiedzy - przede wszystkim na potrzeby dydaktyki. Ciągle bowiem nie znajdziemy - z pewnymi wyjątkami - na polskich uniwersytetach kursów poświęconych chociażby poszczególnym generacjom literatury elektronicznej.

Dyskurs dookoła związków nowych mediów i literatury jest często zniekształcony przez sam przedmiot badania, chętnie przejmuje metafory technologiczne nie do końca adekwatne do opisu określonych zjawisk, czego sztandarowym chyba przykładem jest anachronicze używanie pojęcia hipertekstu w odniesieniu do dzieł powstałych w kulturze druku (przy całkowitym wyparciu znaczenia hipertekstu znanego z ujęć Gérarda Genette’a).

Równie częste jest lekceważenie złożoności problemów wiązanych z wpływem nowych mediów na literaturę, który odbywa się na bardzo różnych poziomach. Mam nadzieję, że udało się zaproponowaną typologię poprzeć stosownymi przykładami, pokazującymi związek z mediami cyfrowymi form literackich, które nie są literaturą elektroniczną i na pierwszy rzut oka nie zdradzają z nią żadnego pokrewieństwa, choć właśnie związane są dość ściśle z doświadczeniem tej formacji medialnej. Poruszają tematy społeczne i pokazują uwikłanie tekstów w rozmaite porządki medialne, społeczne i polityczne.

Na zakończenie chciałbym wspomnieć o artykule Floriana Cramera Post-Digital Literary Studies, który ukazał się w tym samym roku co mój tekst Literatura postelektroniczna... (2016).

Florian Cramer, akademik, medioznawca i artysta, wprowadza i rozpoznaje zjawisko postcyfrowej literatury (Cramer 2016). Dokonuje go jednak na podstawie porządku definicyjnego związanego ze ścisłym rozumieniem cyfrowości jako terminu związanego z teorią sygnałów. A więc tworzy genealogię literatury cyfrowej od ujęć podchodzących do języka ściśle strukturalistycznie oraz w związku z teorią przekaźników. Obnaża w ten sposób chaos definicyjny towarzyszący cyfrowej 
humanistyce, potocznie rozumianej jako subdyscyplina związana z informatyzacją i komputeryzacją. Jak wykazuje Cramer (Cramer 2016: 12), „cyfrowy” odnosi się do wszelkiego rodzaju informacji, które - używając terminu Nelsona Goodmana są „zróżnicowane”: to znaczy podzielone na (a) jednoznacznie policzalne jednostki, które (b) wynikają ze skończonego repertuaru symboli. Medium cyfrowym jest zatem system języka w rozumieniu Ferdinanda de Saussure'a, kaszta zecerska czy maszyna do pisania (więcej o problemach z terminologią „cyfrowości” zob. Cramer 2015: 17-23). W tym sensie rozróżniamy też elektroniczne media analogowe i elektroniczne media cyfrowe ${ }^{6}$.

Zaproponowany przeze mnie w opracowaniu termin postelektroniczności w odniesieniu do literatury można uznać za najbezpieczniejszy z powodu problemu z różnie rozumianą cyfrowością i być może bardziej precyzyjny i neutralny w stosunku do oczekiwań odbiorców.

Co interesujące, w konkluzjach Cramer odnajduje zwiastuny postcyfrowej literatury w praktykach konceptualnych Kennetha Goldsmitha (Cramer 2016: 19).

\section{Bibliografia przedmiotu}

Berry David M., Dieter Michael. 2015. Postdigital Aesthetics: Art, Computatin and Design. London.

Bourdieu Paul. 2001. Reguły sztuki. Andrzej Zawadzki (przeł.). Kraków.

Cramer Florian. 2015. What Is "Postdigital”. W: Postdigital Aesthetics: Art, Computation and Design. David M. Berry, Michael Dieter (przeł.). London. 12-26.

Cramer Florian. 2016. „Post-Digital Literary Studies”. Materialities of Literature nr 4.1. 11-27.

Crary Jonathan. 2015. 24/7. Późny kapitalizm i koniec snu. Dariusz Żukowski (przeł.). Kraków.

Dworkin Craig, Goldsmith Kenneth (red.). 2011. Aganist Expresion. Evanston.

Hayles Katherine N. 2010. Literatura elektroniczna: czym jest?. Sonia Fizek, Mariusz Pisarski (przeł.). http://www.techsty.art.pl/magazyn/magazyn7/literatura_elektroniczna_czym_jest_1.html. (dostęp: 18.01.2020).

Higgins Dick. 2000. Nowoczesność od czasu postmodernizmu oraz inne eseje. Krzysztof Brzeziński (przeł.). Gdańsk.

Humphrey Robert. 1970. „Strumień świadomości - techniki”. Stefan Amsterdamski (przeł.). Pamiętnik Literacki z. 4. 255-283.

${ }^{6}$ Ileż to razy wielu badaczy, tworząc różnice między literaturą tworzoną w środowisku elektronicznym a tą wydawaną na papierze, w odniesieniu do tej drugiej używa jako skrótu myślowego określenia „analogowa”. W ramach samokrytyki mogę przyznać, że mnie również zdarzyło się w przeszłości takie użycie. Brak w Polsce artykułu systematyzującego język obszaru „humanistyki cyfrowej” i literaturoznawstwa zajmującego się literaturą elektroniczną, o czym może świadczyć chociażby mnogość określeń takich jak „literatura elektroniczna”, „literatura cyfrowa”, „hiperliteratura”, „e-literatura”, „e-poezja”, „cyberpoezja”, „cyfrowa poezja analogowa (sic!)" i wiele innych. W niektórych przypadkach określony terminologiczny wybór może mieć znaczenie dla dziedziny badań i jej genealogii. Obecnie pracuję nad dłuższą publikacją dotyczącą języka różnych obszarów (jak i samej) „cyfrowej humanistyki”. 
Jenkins Henry. 2007. Kultura konwergencji. Zderzenie starych i nowych mediów. Małgorzata Bernatowicz, Mirosław Filiciak (przeł.). Warszawa.

Koehn Philipp, Och Franz J., Marcu Daniel. Statistical Phrase-Based Translation, https:// www.researchgate.net/publication/220816913_Statistical_Phrase-Based_Translation. (dostęp: 18.01.2020).

Ludovico Alessandro. 2012. Postdigital Print: The Mutation of Publishing since 1894. Rotterdam.

Małecka Alicja, Marecki Piotr. 2018. Przekład literatury konceptualnej. Studium przypadku lokalizacji Paint the Rock Shiva Kotechy jako Namaluj Popka. W: Przekłady literatur słowiańskich t. 9, cz. 1. Katarzyna Majdzik (red.). Katowice. 99-123.

Małecka Alicja, Marecki Piotr, Spodaryk Mikołaj (red.). 2015. Ha!art nr 50.

Och Franz. 2006. Statistical Machine Translation Live. https://ai.googleblog.com/ 2006/ 04/statistical-machine-translation-live.html. (dostęp: 18.01.2020).

Okulska Inez. 2016. „Od przekładu intersemiotycznego do produktów typu tie-in, czyli transmedialny storytelling jako strategia tłumaczenia”. Forum Poetyki, jesień. 56-67.

Place Vanessa, Fitterman Robert. 2013. Notes on Conceptualisms. New York.

Spodaryk Mikołaj. 2016. „Literatura postelektroniczna? Od literatury elektronicznej do kartki papieru, czyli podróż powrotna, z bagażem nowych doświadczeń". Annales Universitatis Paedagogicae Cracoviensis. Studia de Cultura nr 8.2. 117-129.

Ślęzak Piotr. 2012. Umowy w zakresie współczesnych sztuk wizualnych. Warszawa.

Woźniakiewicz-Dziadosz Maria. 2012. Hiperpowieść albo sieć w powieści. Lublin.

\section{Bibliografia podmiotu}

Bartnicki Krzysztof. 2012. Da Capo al Finne. Warszawa.

Jarry Alfred. 2015. Ubu Król. Alicja Małecka, Piotr Marecki (przeł. z języka francuskiego za pomocą Tłumacza Google). Kraków.

Marecki Piotr. 2016. Interes. Kraków.

Marecki Piotr. 2017. Wiersze za sto dolarów. Kraków.

Morrison Yedda. 2011. Darkness. Los Angeles.

Morrison Yedda. 2018. Ciemności. Mikołaj Spodaryk (przeł.). Kraków.

Zultanski Steven. 2010. PAD. Los Angeles.

\section{Streszczenie}

Niniejszy tekst dotyczy polskich przykładów pisarstwa konceptualnego umieszczonego w kontekście dyskursu postmedialnego. Stanowi także propozycję typologii i wstępnej systematyzacji relacji literatury i mediów elektronicznych. Na przykładzie polskich utworów podjęto próbę wyjaśnienia specyfiki pisarstwa konceptualnego. Zaznaczono jej interdyscyplinarną problematykę oraz wykazano zastosowanie przedstawionej w pierwszej części artykułu typologii. Tekst jest rozwinięciem niektórych tez z artykułu Literatura postelektroniczna? Od literatury elektronicznej do kartki papieru, czyli podróż powrotna, z bagażem nowych doświadczeń (Spodaryk 2016), opublikowanego w „Annales Universitatis Paedagogicae Cracoviensis. Studia de Cultura", nr 8.2, pod red. Agnieszki Ogonowskiej. 


\title{
Conceptual writing and new media in the era of convergence. A study of Polish experimental works
}

\begin{abstract}
The following paper concerns Polish examples of conceptual writing against the context of post-media discourse. It also contains a proposal for typology and preliminary systematisation of the relationship between literature and electronic media. On the basis of Polish works, an attempt has been made at explaining the features of conceptual writing. Its interdisciplinary problematics has been indicated and the application of the typology (presented in the first part of the paper) has been demonstrated. This text is a development of some of the theses presented in the paper 'Literatura postelektroniczna?' 'Od literatury elektronicznej do kartki papieru, czyli podróż powrotna, z bagażem nowych doświadczeń’ (Spodaryk 2016), published in: Annales Universitatis Paedagogicae Cracoviensis. Studia de Cultura, no. 8.2, edited by Agnieszka Ogonowska, Kraków 2016.
\end{abstract}

Słowa kluczowe: pisarstwo konceptualne, postcyfrowość, literatura eksperymentalna

Key words: conceptual writing, post-digitality, experimental literature

Mikołaj Spodaryk - mgr, kulturoznawca, kurator i animator kultury. Przygotowuje doktorat poświęcony eksperymentalnym strategiom pisarskim i kształtowi polskiego pola literackiego po 1989 roku. 